\title{
PENTINGNYA KEBERADAAN DPD RI SEBAGAI LEMBAGA PENYEIMBANG DI REPUBLIK INDONESIA
}

\author{
Oleh : MAHYU DARMA*)
}

\begin{abstract}
$D P D$ which is representative of the area to be balancing on strengthening the parliamentary system in Indonesia. DPD into mediation forum aspirations of the community and region as well as other interests. If viewed from the constitutional DPD also present to strengthen the parliamentary system in the legislative process. $D P R$ and DPD which together perform the functions of legislation, budget and supervision, it is expected the two legislative branches can provide meaningful input to the government so as to create synergies between national interests, political interests of the Indonesian people and the regional interests in national policy formulation.
\end{abstract}

\section{ABSTRAK}

DPD yang merupakan wakil dari daerah mampu menjadi penyeimbang dalam penguatan sistem parlemen di Indonesia. DPD menjadi forum mediasi aspirasi masyarakat dan daerah serta kepentingan lainnya. Jika dilihat dari ketatanegaraan DPD juga hadir untuk menguatkan sistem parlemen dalam proses legislasi. DPR dan DPD yang bersama-sama menjalankan fungsi-fungsi legislasi, anggaran, dan pengawasan, diharapkan kedua lembaga perwakilan rakyat ini dapat memberikan masukan yang berarti bagi pemerintah sehingga tercipta sinergi antara kepentingan nasional, kepentingan politik rakyat Indonesia dan kepentingan daerah dalam perumusan kebijakan nasional.

\section{Pendahuluan}

Undang-Undang Dasar Negara Republik Indonesia Tahun 1945 (Undang-undang Dasar Tahun 1945) menegaskan fungsi, tugas, dan wewenang Dewan Perwakilan Daerah Republik Indonesia (DPD RI) sebagai lembaga negara (main state organ) di ranah legislasi yang bersanding dengan Dewan Perwakilan Rakyat Republik Indonesia (DPR RI).

Keberadaan DPD memiliki urgensi tinggi dalam sistem ketatanegaraan di Indonesia. DPD yang merupakan wakil dari daerah mampu menjadi penyeimbang (kamar kedua) dalam penguatan sistem parlemen di Indonesia. Sebagai kamar kedua, DPD menjadi forum mediasi aspirasi masyarakat dan daerah serta kepentingan lainnya. Jika dilihat dari ketatanegaraan DPD juga hadir untuk menguatkan sistem parlemen dalam proses legislasi.

\footnotetext{
${ }^{*}$ Dewan Perwakilan Daerah Republik Indonesia
} 
Gagasan pembentukan DPD tidak terlepas dari : 1) adanya tuntutan demokratis, bahwa pengisian angggota lembaga negara senantiasa dapat mengikutsertakan rakyat pemilih, sehingga keberadaan Utusan Daerah dan Utusan Golongan dalam komposisi MPR yang semula ditunjuk oleh unsur pemerintah digantikan dengan pembentukan sebuah lembaga yaitu DPD. 2) pembentukan DPD juga melekat dengan semakin maraknya tuntutan penyelenggaraan otonomi daerah, yang jika tidak dikendalikan dengan baik berujung pada tuntutan separatisme. Dalam pada itu, DPD juga terembani hakikat sebagai lembaga negara yang memiliki fungsi integrasi sebagaimana diamanatkan sila ketiga Pancasila, yakni Persatuan Indonesia, sehingga setiap kepentingan daerah senantiasa dalam koridor Negara Kesatuan Republik Indonesia (NKRI).

PENTINGNYA KEBERADAAN DPD RI SEBAGAI LEMBAGA PENYEIMBANG DI REPUBLIK INDONESIA.

Hakikat keberadaan DPD disamping Pasal 22 Undang-undang Dasar, juga harus mengalir dari pasalpasal yang terkait dengan Pemerintah Daerah, antara lain Pasal 18 ayat (1) Perubahan Ketiga Undang-undang Dasar 1945, bahwa: "Negara Kesatuan
Republik Indonesia dibagi atas daerahdaerah provinsi dan daerah provinsi itu dibagi atas kabupaten dan kota mempunyai pemerintah daerah." Hal tersebut perlu ditegaskan, mengingat saat ini dari 34 provinsi masih terdapat perbedaan sumber daya alam dan sumber daya manusia, bahkan sumber dana yang cukup signifikan bagi terselenggaranya otonomi daerah yang relatif sama.

Dalam kondisi demikan dapat diasumsikan, tiap anggota DPD diembani dengan situasi, kondisi dan kepentingan masing-masing provinsi yang juga sangat beragam yang pada akhirnya mungkin akan mempengaruhi keutuhan NKRI sehingga dibutuhkan antisipasi bagi terselenggaranya fungsi integrasi.

Dalam konteks ini, DPD secara langsung menjalankan fungsi integrasi bangsa dengan mencoba merekatkan dan meningkatkan derajat kebersatuan dari keragaman yang ada di nusantara ini. Persoalan-persoalan lokal yang relevan dengan wilayah tugas DPD dicoba dinasionalkan (menasionalkan isu-isu dan permasalahanpermasalahan lokal yang relevan) sehingga masyarakat daerah merasa diperhatikan dan melalui para wakilnya di DPD membahasnya sebagai agenda nasional berbasis kepentingan daerah. 
Sebaliknya, isu-isu srategis nasional dicoba disosialisasikan dan atau dikomunikasikan secara langsung dengan masyarakat daerah, sehingga apa yang terjadi dan atau menjadi isu nasional bisa secara relatif dipahami oleh masyarakat lokal (melokalkan atau membumikan isu dan agenda nasional).

Salah satu masalah penting yang dihadapi oleh Indonesia (pasca Orde Baru) adalah pelaksanaan otonomi daerah dalam arti sesungguhnya, tidak hanya sebagai pemanis di bibir seperti pada masa Orde Baru. Otonomi daerah merupakan sebuah cara untuk mengurangi dampak negatif yang ditimbulkan oleh kekeliruan dalam manajemen hubungan pusat-daerah yang dilakukan oleh Orde Baru.

Lebih jauh lagi, DPD diharapkan dapat menyuarakan kepentingan daerah dalam pembicaraan Rancangan Undang-undang (RUU)

dan pelaksanaan tugas-tugas pengawasannya. Sebelum DPD terbentuk, lembaga yang menjalankan tugas tersebut adalah DPR, berbagai organisasi massa (ormas), dan warga masyarakat tertentu. Namun, DPR yang "lebih" menyuarakan kepentingan partai politik (parpol) diperkirakan tidak bisa terlalu fokus pada kepentingan daerah. Sedangkan ormas dan warga masyarakat adalah kekuatan ekstra parlementer yang lebih merupakan kekuatan yang berusaha mempengaruhi lembaga-lembaga politik formal, namun tidak terlibat langsung dalam proses pembuatan keputusan. DPD diharapkan menjadi kekuatan parlementer yang mempunyai pengaruh yang kuat dalam proses pembuatan keputusan sehingga DPD dapat mengakomodasikan berbagai kepentingan daerah ke dalam kebijakan-kebijakan pemerintah pusat.

Dengan demikian, DPD menjadi lembaga penyeimbang bagi DPR dan pemerintah. DPR melihat masalahmasalah nasional dari sudut kepentingan politik tertentu dari sekelompok rakyat Indonesia (tanpa memperhatikan daerah). Sedangkan DPD berusaha memberikan warna kepentingan daerah dalam kebijakankebijakan nasional sehingga tidak terjadi benturan antara kepentingan nasional dan kepentingan daerah. Hal ini adalah persyaratan bagi terbentuknya hubungan yang harmonis antara pemerintah pusat dan daerah.

Pada tingkat nasional, pemerintah pusat berusaha agar kepentingan nasional dapat terwujud. Dengan adanya DPR dan DPD yang bersama-sama menjalankan fungsifungsi legislasi, anggaran, dan pengawasan, diharapkan kedua lembaga perwakilan rakyat ini dapat 
memberikan masukan yang berarti bagi pemerintah sehingga tercipta sinergi antara kepentingan nasional, kepentingan politik rakyat Indonesia dan kepentingan daerah dalam perumusan kebijakan nasional.

Alhamdulillah, dalam usianya yang memasuki 12 tahun di periode ketiga ini, telah terjadi evolusi fungsi legislasi DPD, juga agregasi dan artikulasi kepentingan. Paling mendasar ialah perwujudan proses legislasi model tripartit antara DPR-DPD bersama Presiden (Pemerintah). Pasca-putusan Mahkamah Konstitusi (MK) tanggal 27 Maret 2013 Nomor 92/PUU-X/2012 di perkuat juga dengan putusan MK Nomor 79/PPUU-X/2014 tanggal 22 September 2015 disamping inwal konstitusionalitas, pembahasan tripartit juga kemandirian anggaran, fungsi legislasi DPD semakin memperkokoh keyakinan senator untuk membangun sinergitas kelembagaan legislatif di tingkat nasional dan lokal, yaitu strategic alliance yang tepat guna mewujudkan checks and balances.

Target politiknya ialah mewujudkan efektivitas dan efisiensi mekanisme legislasi yang bermanfaat bagi masyarakat dan daerah, setelah pimpinan/anggota DPD dan alat kelengkapannya (komite-komite, badan dan panitia) menyerap, menghimpun, menampung, dan menindaklanjuti aspirasi seiring pemenuhan tuntutan berbangsa dan bernegara.

Wujud DPD sebagai representasi daerah sudah makin terlihat dengan jelas. Total 52 dari 160 RUU dalam Program Legislasi Nasional (Prolegnas) Tahun 2015-2019 atau 32\% substansi atau materiilnya, sesuai dengan usulan DPD.

Adapun Prolegnas tahun 2015 usulan DPD berjumlah 12 dari 37 RUU atau 44\%, sedangkan pada tahun 20152016 ada 3 RUU Inisiatif yaitu RUU Wawasan Nuasantara, RUU BUMNBUMD, dan RUU Ekonomi kereatif yang direncanakan selesai pembahasannya pada tahun 2016 ini.

Kemudian, dalam kaitan dengan Pemerintah Daerah sendiri, DPD terlibat langsung dalam revisi Undang-Undang Pemerintah Daerah termasuk pembahasannya bersama DPR yang kemudian melahirkan Undang-Undang Nomor : 23/Tahun 2014 Tentang Pemerintah Daerah. Selain itu, para anggota DPD sudah melibatkan diri dan hadir pada setiap Musyawarah Rencana Pembangunan (Musrenbang) di tingkat Provinsi sebagai fungsi pengawasan mulai dari penyusunan hingga penyerapan anggaran, baik yang dari APBN maupun APBD itu sendiri. Tidak itu saja, DPD juga memberika advokasi politik, adapun hasil advokasi politik 
tersebut adalah terwujudnya pembangunan Bandara Kualanamu di Medan Provinsi Sumatera Utara, Pembangunan jalan tol Denpasar Nusadua di Provinsi Bali, menginisiasi penurunan tarif listrik, dan pemekaran wilayah. Disamping itu pada tanggal 1 Oktober 2014 usul RUU inisiatif DPD yaitu Undang-Undang Nomor : 32 Tahun 2014 tentang Kelautan disetujui/disahkan dalam Paripurna DPR RI.

\section{Penutup}

Banyak hal yang telah dilakukan DPD guna mewujudkan cita-citanya dalam membangun serta mempercepat kesejahteraan daerah, disamping inisiasi pembuatan regulasi, advokasi politik juga merupakan sebuah afirmasi kebijakan DPD. Oleh karena itu kehadiran DPD di Republik tercinta ini, merupakan wujud penting dalam kesatuan dan persatuan bangsa Indonesia. 